\title{
ATR-FTIR spectroscopy reveals involvement of lipids and proteins of intact pea pollen grains to heat stress tolerance
}

\author{
Rachid Lahlali ${ }^{1}$, Yunfei Jiang ${ }^{2}$, Saroj Kumar ${ }^{1}$, Chithra Karunakaran $^{1}{ }^{*}$, Xia Liu $^{1}$, Ferenc Borondics ${ }^{1}$, \\ Emil Hallin ${ }^{1}$ and Rosalind Bueckert ${ }^{2}$
}

${ }^{1}$ Canadian Light Source, Saskatoon, SK, Canada

2 Department of Plant Sciences, University of Saskatchewan, Saskatoon, SK, Canada

\section{Edited by:}

Andreia Michelle Smith-Moritz, Lawrence Berkeley National

Laboratory, USA

\section{Reviewed by:}

Victoria Fernandez, Technical University of Madrid, Spain Jason Lupoi, Joint BioEnergy Institute/University of Queensland, USA

\section{${ }^{*}$ Correspondence:}

Rachid Lahlali and Chithra Karunakaran Canadian Light Source, 44 Innovation Boulevard, Saskatoon, SK S7N 2V3, Canada

e-mail: lahlali.r@gmail.com;

chithra.karunakaran@lightsource.ca
With climate change, pea will be more frequently subjected to heat stress in semi-arid regions like Saskatchewan during flowering. The pollen germination percentage of two pea cultivars was reduced by heat stress $\left(36^{\circ} \mathrm{C}\right)$ with an important decrease in cultivar 'CDC Golden' compared to 'CDC Sage.' Lipids, protein and other pollen coat compositions of whole intact pollen grains of both pea cultivars were investigated using mid infrared (mid-IR) attenuated total reflectance (ATR)-Fourier transform infrared (FTIR) spectroscopy. Curve fitting of ATR absorbance spectra in the protein region enabled estimation and comparison of different protein secondary structures between the two cultivars. CDC Sage had relatively greater amounts of $\alpha$-helical structures (48.6-43.6\%; band at $1654 \mathrm{~cm}^{-1}$ ) and smaller amounts of $\beta$-sheets (41.3-46\%) than CDC Golden. The CDC Golden had higher amounts of $\beta$-sheets (46.3-51.7\%) compared to $\alpha$-helical structures (35.3-36.2\%). Further, heat stress resulted in prominent changes in the symmetrical and asymmetrical $\mathrm{CH}_{2}$ bands from lipid acyl chain, ester carbonyl band, and carbohydrate region. The intensity of asymmetric and symmetric $\mathrm{CH}_{2}$ vibration of heat stressed $\mathrm{CDC}$ Golden was reduced considerably in comparison to the control and the decrease was higher compared to CDC Sage. In addition, CDC Golden showed an increase in intensity at the oxidative band of $3015 \mathrm{~cm}^{-1}$. These results reveal that the whole pollen grains of both pea cultivars responded differently to heat stress. The tolerance of CDC Sage to heat stress (expressed as pollen germination percentage) may be due to its protein richness with $\alpha$-helical structures which would protect against the destructive effects of dehydration due to heat stress. The low pollen germination percentage of CDC Golden after heat stress may be also due to its sensitivity to lipid changes due to heat stress.

Keywords: lipids, protein secondary structures, pollen grains, pea, heat stress, infrared ATR-FTIR spectroscopy

\section{INTRODUCTION}

Heat stress is one of the key environmental stresses affecting yield of pea cultivars (Psium sativum L.) under semi-arid agricultural conditions in Saskatchewan. Heat stress occurs when temperatures are high enough for sufficient time to cause irreversible damage to plant function or development. Heat stress is a complex function of temperature, duration, and rate of increase in temperatures. Hall $(1990,1993)$ reviewed the detrimental effects of heat stress on the reproductive developments in cowpea, common bean, tomato, wheat, rice, maize, and sorghum. Direct evidence of heat stress effects on grain yield is provided by studies on different plants that are subjected to various increments of elevated temperatures under field conditions in: cowpea (Nielsen and Hall, 1985); Calabrian pine (Tilki and Dirik, 2007); and elm (Cicek and Tilki, 2007).

The sensitivity of a flower to heat stress is influenced by its position on the inflorescence and the presence or absence of "flowers on the stem below it." In pea, daytime temperatures of $32^{\circ} \mathrm{C}$ do not immediately result in sterile flowers but result in delayed abortion of reproductive structures in distal flowers, whereas the more proximal flowers in a node are not affected (Guilioni et al., 1997).
Moderate heat stress causes changes in the carbon metabolism that is likely to trigger the abortion of reproductive organs in these distal flowers (Guilioni et al., 1997).

Temperatures can also affect pollen grains during transport to and germination upon the stigma, as well as during development in the anther. Mature pollen grains are generally resistant to temperature stress applied after dehiscence, but detailed investigations have been carried out only in a few instances. In tomato, applying mild heat stress after dehiscence reduces fruit set, and the differences in fruit set with controls are not significant (Sato et al., 2002).

A severe heat stress treatment of Brassica pollen revealed that pollen grains germinate after exposure to $60^{\circ} \mathrm{C}$ for $4 \mathrm{~h}$. Seed set after pollination with pollen treated at $75^{\circ} \mathrm{C}$ or at $60^{\circ} \mathrm{C}$ for $24 \mathrm{~h}$ is reduced, but pollination with other samples led to normal seed set (Rao et al., 1992). One possible explanation for this observation may be that pollen that germinated on the stigma can overcome any effects of the heat treatment. It is also possible that stigmas may be over-pollinated, thereby reducing germination rates. Further, pollination was performed only with heat treated pollen and no selection on pollen for tube growth rate was conducted. Therefore, 
pollen performance may be affected by mixed pollination as it occurs in natural environments. Accordingly, plants may experience different types of stress at different developmental stages and these mechanisms of response to stress may vary in different tissues and between plant species (Wahid et al., 2007).

Pollen has a wall which is completely different from any other plant structures. The pollen wall is multilayered, derived from both the developing pollen and sporophytic cells of the anther, and consists of material that is highly resistant to degradation, making it an important determinant of pollen viability (Taylor and Hepler, 1997; Wahid et al., 2007). The surface of the pollen wall, also known as the pollen coat in some plant species, consists of materials like tryphine or protein-rich matrix, pollenkitt (Taylor and Hepler, 1997). This sticky substance may contain lipids, proteins and phenolic compounds, and can be present in substantial amounts in entomophilous species. The functions of the pollen coat are to facilitate pollen transfer through sticking to insects and protection against environmental stress, but the lipids and proteins of the pollen coat may also play an important role in the adhesion of pollen grains to the stigma (Dickinson et al., 2000). Studies of mechanisms of tolerance of pea cultivars to heat stress in semi-arid conditions are still in their infancy and the role of the pollen coat in pea tolerance to heat stress is unclear. We hypothesized that heat resistance mechanisms are present in pollen in some pea genotypes. Genotypes with pollen that has heat resistance will maintain pollen vigor and increased pollen germination, allowing for a greater success in fertilization and seed set in warm temperatures. Such a mechanism or mechanisms should be evident and detectable in the physical structure of pollen, by maintained wall integrity, protein and lipid integrity, and ultimately demonstrated in the ability of pollen grains to germinate. Therefore, we proposed for the first time, the use of mid infrared (mid-IR) attenuated total reflectance (ATR)-Fourier transform infrared (FTIR) spectroscopy as a suitable tool to understand pea pollen surface composition and its potential role in tolerance to heat stress.

The FTIR spectroscopy has recently become an established method for quick and reliable analysis of the composition of agricultural materials such as grain, pollen, plants, forages, and soils (Sowa et al., 1991; Chamel and Marechal, 1992; Sowa and Connor, 1995; Ivanova and Singh, 2003; Alonso-Simon et al., 2004; Bernier et al., 2013; Bruckman and Wriessnig, 2013; Zimmermann and Kohler, 2014). The FTIR spectroscopy has also been successfully used for detecting and identifying microorganisms in food products (Oberreuter et al., 2002; Winder and Goodacre, 2004; Filip et al., 2006; Oliveira et al., 2009). The FTIR spectroscopy is advantageous because it has many distinct peaks amenable to spectral interpretation according to diagnostic bands (Buta et al., 1997; Alonso-Simon et al., 2004; Kong and Yu, 2007).

The objective of this work was to use ATR-FTIR spectroscopy to analyze intact pollen grains of two pea cultivars cultivated largely in the province of Saskatchewan. The surface compositions of pollen from control and heat stressed plants of two cultivars, CDC Golden and CDC Sage, were studied and compared. The changes in the pollen surface composition of both cultivars were compared to the differences in pollen development observed for both pea cultivars under controlled conditions.

\section{MATERIALS AND METHODS PLANTS}

Pea cultivars, CDC Golden and CDC Sage were tested in this study. Plants were grown in a $2 \mathrm{~L}$ volume (three plants per pot) using Sunshine Gro mix and slow-release fertilizer in the phytotron facility at the University of Saskatchewan. Plants were thinned to two plants per pot $\sim 2$ weeks after seeding. Plants received the first application of half strength Hoagland's culture solution (Zhao et al., 2005) at 3 weeks after seeding and the second application at the early flowering stage. The nutrient solution with $\mathrm{pH}$ $6.05 \pm 0.05$ was made of $2.5 \mathrm{ml}$ of the following solution into $1 \mathrm{~L}$ distilled water: $\mathrm{K}_{2} \mathrm{PO}_{4}\left(34.84 \mathrm{~g} \mathrm{~L}^{-1}\right), \mathrm{KNO}_{3}\left(101.11 \mathrm{~g} \mathrm{~L}^{-1}\right)$, $\mathrm{Ca}\left(\mathrm{NO}_{3}\right)_{2}{ }^{*} \mathrm{H}_{2} \mathrm{O}\left(236.15 \mathrm{~g} \mathrm{~L}^{-1}\right), \mathrm{MgSO}_{4}{ }^{*} 7 \mathrm{H}_{2} \mathrm{O}\left(98.59 \mathrm{~g} \mathrm{~L}^{-1}\right)$, trace elements $\left(0.57 \mathrm{~g} \mathrm{~L}^{-1} \mathrm{H}_{3} \mathrm{BO}_{3}, 0.36 \mathrm{~g} \mathrm{~L}^{-1} \mathrm{MnCl}_{2} * 4 \mathrm{H}_{2} \mathrm{O}\right.$, $\left.0.04 \mathrm{~g} \mathrm{~L}^{-1} \mathrm{ZnSO}_{4}{ }^{*} 7 \mathrm{H}_{2} \mathrm{O}, 0.016 \mathrm{~g} \mathrm{~L}^{-1} \mathrm{CuSO}_{4}{ }^{*} 5 \mathrm{H}_{2} \mathrm{O}\right)$. Each pot received $500 \mathrm{ml}$ of the solution each time. Soil medium water moisture was monitored carefully to avoid drought stress, and watered as necessary with distilled water. Plants were grown in growth chambers at $24 / 18^{\circ} \mathrm{C}$ day/night temperatures with a $16 \mathrm{~h}$ photoperiod in each $24 \mathrm{~h}$ cycle in a phytotron, and then were transferred to a second growth chamber to expose them to high temperatures for 7 days when the flowers at the second fruiting node of main stem were fully open. The heat stress temperature assessed in this study was $36 / 18^{\circ} \mathrm{C}$ day/night. The control plants continued to stay in the $24 / 18^{\circ} \mathrm{C}$ regime. Mature pollen grains of CDC Golden and CDC Sage at 24 and $36^{\circ} \mathrm{C}$ were collected from the slightly opened flowers on the fourth day after plants were exposed to high temperature.

\section{GERMINATION TEST}

In vitro pollen germination was evaluated using a pollen germination medium. Pollen grains were collected from plants in the control regime with the temperature of $24 / 18^{\circ} \mathrm{C}$ day/night. The medium consisted of $15 \mathrm{~g}$ sucrose $\left(\mathrm{C}_{12} \mathrm{H}_{22} \mathrm{O}_{11}\right), 0.03 \mathrm{~g}$ calcium nitrate $\left[\mathrm{Ca}\left(\mathrm{NO}_{3}\right)_{2} 4 \mathrm{H}_{2} \mathrm{O}\right]$, and $0.01 \mathrm{~g}$ boric acid $\left(\mathrm{H}_{3} \mathrm{BO}_{3}\right)$ dissolved in $100 \mathrm{~mL}$ of deionized water (Shivanna and Rangaswamy, 1992; Salem et al., 2007). To solidify the medium, $0.5 \mathrm{~g}$ of agar was added to medium. Fresh pollen was collected from all anthers of slightly opened flowers at 5-6 h after the $16 \mathrm{~h}$ photoperiod began, which compared to 9:00-10:00 am in the field during summer. Pollen grains were collected from the anthers from between 10:00 and 11:00 am, was dusted onto the germination medium on microscope slides, and then microscope slides were placed individually in $9 \mathrm{~cm}$ diameter petri dishes with moistened filter paper. The lids of petri dishes were sealed with parafilm to maintain high humidity. The slides were placed in each of two growth chambers with two temperature treatments at $24 / 18$ and $36 / 18^{\circ} \mathrm{C}$ day/night temperatures. After $10 \mathrm{~h}$ of incubation, pollen grains (100 grains per replication, five replications per treatment) were counted for germination rate using direct microscopic observation. Germinated pollen grains were determined when the length of the pollen tube was more than the diameter of pollens grains (Shivanna and Rangaswamy, 1992; Salem et al., 2007). Pollen germination percentage was calculated by dividing the number of germinated pollens by the total number of pollens and expressed as a percentage. Arcsine transformation was used to normalize percentage data distribution and then analyzed using one-way ANOVA procedure of the 
Statistical Analysis System (SAS Institute, version 9.1, Cary, NC, USA). Means values were compared using Fisher's LSD test at statistical significance of $P \leq 0.05$.

\section{ATR-FTIR SPECTROSCOPY}

Mature pollen samples from four replicates were collected by dusting pollen grains from anthers harvested from fresh flowers $\sim 45$ min prior to the ATR reflectance measurement. The pollens on $\mathrm{CaF}_{2}$ slides. were kept in a petri dish with moistened filter paper to minimize possible dehydration until the measurement time. All FTIR spectroscopy data were collected at the mid infrared beamline (01B1-1) at the Canadian Light Source using the glowbar source (silicon carbide) as the infrared source. The pollen surface composition was determined by ATR method using a germanium crystal (20x objective, $100 \mu \mathrm{m}$ crystal surface, angle of incidence $=45^{\circ}$ ) attached to a Bruker Hyperion, 2000 confocal microscope (Bruker Optics, Ettlingen, Germany) with a $\mathrm{KBr}$ beam splitter and liquid nitrogen cooled mercury cadmium telluride (MCT) detector. Each IR spectrum was recorded in the mid infrared range of $4000-800 \mathrm{~cm}^{-1}$ at a spectral resolution of $2 \mathrm{~cm}^{-1}$. The ATR germanium crystal was in contact with the pollen after applying the standard pressure setting. The penetration depth was further increased by maximizing the infrared signal from the sample during which the pollen grain was crushed. Each sample spectrum is an average of 512 scans, and normalized using a background reflectance spectrum (average of 1024 scans) from a fresh gold surface. Spectra from 15 individual pollen grains per combination (Bruker's OPUS Pro 7.0 at 1 number of ATR reflexions, $45^{\circ}$ angle of incidence, and 1.5 mean refraction index of sample) of cultivar and heat stress treatment were collected and an extended ATR correction was applied for each spectrum before data analysis.

To estimate lipids, phosphate, and carbohydrate contents the ATR spectra were normalized using the protein peak (1700$1600 \mathrm{~cm}^{-1}$ ) and for the protein content analysis the ATR spectra were normalized using the lipid-ester peak at $1740 \mathrm{~cm}^{-1}$. The estimation of components such as phosphate and carbohydrate were determined by integrating the area under the specific bands. The area integration were determined using the the OPUS integration method C. This method allowed to choose four points, in which the two points were considered left and the right of the interested band, and another two points were far away for the baseline on each side to get a straight baseline.

\section{PEA PROTEIN SECONDARY STRUCTURES}

The pea protein secondary structure analysis was carried out by curve fitting using a program Kinetics, written by Goormaghtigh et al. (2006) using Matlab (version R2008, Mathworks Inc.). First, the second derivative spectra were calculated from the ATR-FTIR spectra after smoothing over two consecutive points. The absorption bands at low wavenumber were free of features from water vapor as judged from the peaks above $1750 \mathrm{~cm}^{-1}$. A straight baseline passing through the ordinate at 1700 and $1610 \mathrm{~cm}^{-1}$ was subtracted before the curve fitting. The baseline was again modified by the least-squares curve fitting program which allows for a horizontal baseline to be adjusted as an additional parameter to obtain the best fit. The second derivative spectrum was used to determine the initial peak positions for curve fitting and the peaks were fitted using Voigt functions (Goormaghtigh etal., 1990). In curve fitting, each component is a mixture of Lorentzian and Gaussian lineshapes. The area under the entire band was considered 100\% and each component after fitting was expressed as a percent fraction.

\section{RESULTS}

\section{PEA POLLEN GERMINATION}

The effect of heat stress on pollen germination was evaluated for both pea cultivars CDC Golden and CDC Sage (Figure 1). Results show that under normal conditions, there was no difference between both cultivars in the pollen germination percentage, whereas under heat stress conditions $\left(36 / 18^{\circ} \mathrm{C}\right)$, percentage pollen germination was reduced by 30 and 55\% in CDC Sage and CDC Golden, respectively. The heat stress reduced pollen germination in both cultivars and CDC Golden was affected more than CDC Sage.

\section{PEA POLLEN PROTEIN}

The FTIR reveals molecular-vibrational transitions and provides characteristic information on molecular compositions (Griffiths, 1978). Figures 2 and 3 show the absorbance (A) and second derivative spectra (B) of pollen from both cultivars, at control and high temperature. The amide I band (from 1700 to $1600 \mathrm{~cm}^{-1}$ ) is mainly associated with the $\mathrm{C}=\mathrm{O}$ stretching vibration and is directly related to the protein backbone conformation (Sowa et al., 1991; Wolkers and Hoekstra, 1997; Fernandes etal., 2013). In the spectra of pollen, at least two main absorption peaks were observed at 1638 and $1654 \mathrm{~cm}^{-1}$ (Figures 2B and 3B) in the amide I region. Both the peaks are sensitive to hydrogen bonding and coupling between transition dipoles of adjacent peptide bonds and hence, indicate different secondary structures (Sowa et al., 1991; Wolkers and Hoekstra,

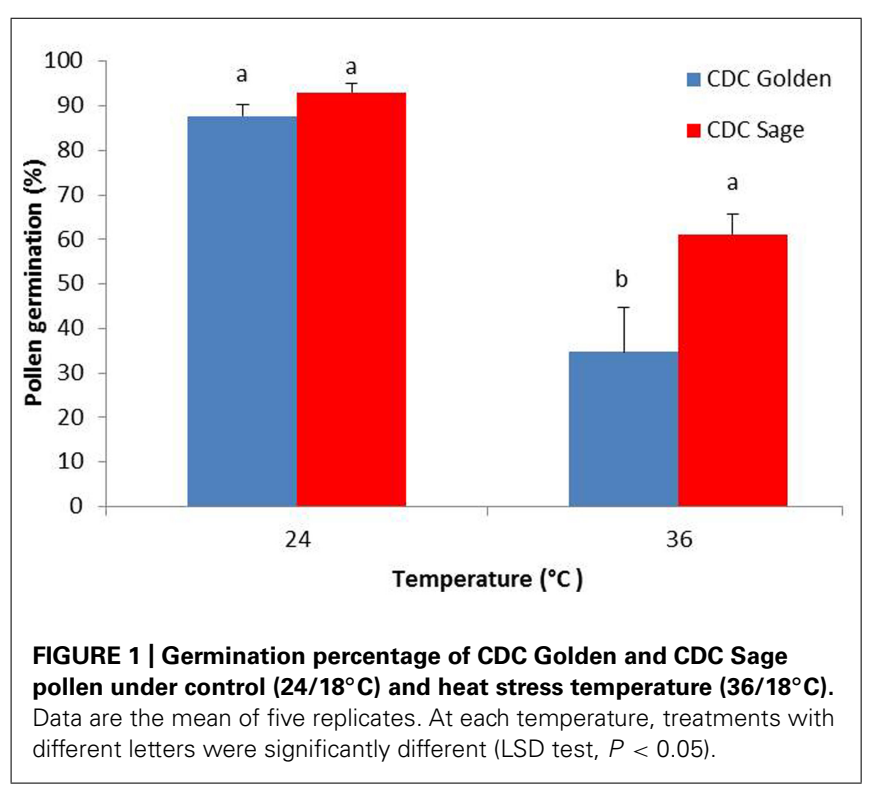




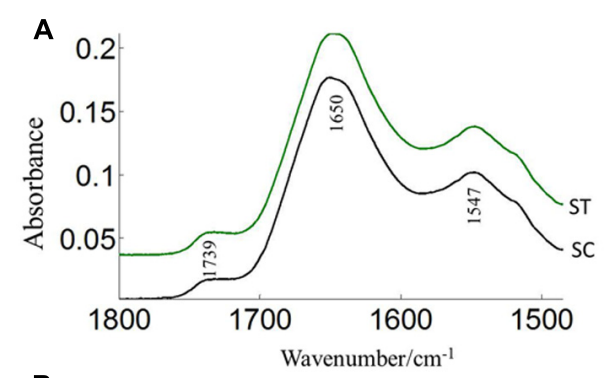

B

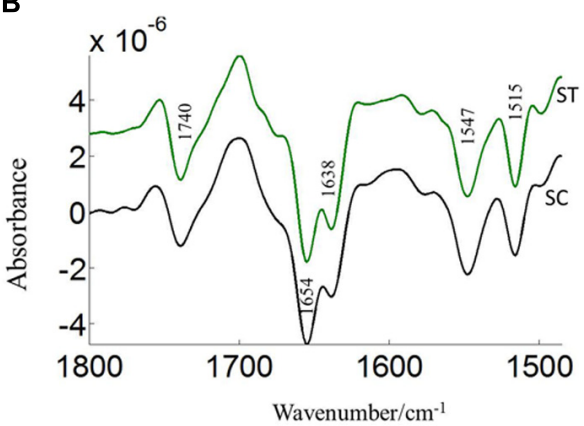

FIGURE 2 | Average protein (1800-1500 $\mathrm{cm}^{-1}$ ) absorbance (A) and respective second derivative (B) spectra of heat stressed (ST) and control (SC) pollen of CDC Sage. Data are means of 15 individual pollen spectra per treatment combination.

1997). The absorption band positions identified in this study are in agreement with previous work on pollen (Wolkers and Hoekstra, 1995). In the literature (Wolkers and Hoekstra, 1995), the following bands in the amide I region are assigned: $\beta$-sheets/turn (1692-1690 $\left.\mathrm{cm}^{-1}\right)$, turn or loops $\left(1674-1673 \mathrm{~cm}^{-1}\right)$, helical segments and $\alpha$-helices $\left(1650-1654 \mathrm{~cm}^{-1}\right), \beta$-sheets $\left(1638 \mathrm{~cm}^{-1}\right)$ and protein side chains, as well as contribution of cell wall material at $1615 \mathrm{~cm}^{-1}$ (Wolkers and Hoekstra, 1995). Spectral differences between control pollen grains of the both cultivars were also observed.

Pollens from the two pea cultivars were subjected to two temperature regimes as described previously. The use of the extreme temperature of $36^{\circ} \mathrm{C}$ is justified by the semi-arid conditions in which pea cultivars are usually grown. To compare protein changes of control and heat stressed pea pollen grains, FTIR spectra were normalized using the $\mathrm{C}=\mathrm{O}$ bond of the ester peak at $1740 \mathrm{~cm}^{-1}$. The intensity of the $1650-1654 \mathrm{~cm}^{-1}$ band was higher in control pollen and was reduced after heat stress for both cultivars (Table 1). In addition to lipids and protein secondary structures, Table 1 show spectral differences in nucleotides $\left(996 \mathrm{~cm}^{-1}\right)$, carbohydrates $\left(1053 \mathrm{~cm}^{-1}\right)$, phosphate $\left(P=0,1240 \mathrm{~cm}^{-1}\right)$ between both CDC cultivars with/out heat stress.

\section{PEA POLLEN PROTEIN SECONDARY STRUCTURES}

The protein secondary structures of CDC Sage and CDC Golden pollen were also estimated for control and temperature treatment. Figures $\mathbf{4}$ and $\mathbf{5}$ show the fitted amide I component bands of pollen protein in CDC Sage and CDC Golden. This curve fitting is based on the second derivatives of the original spectrum, which is

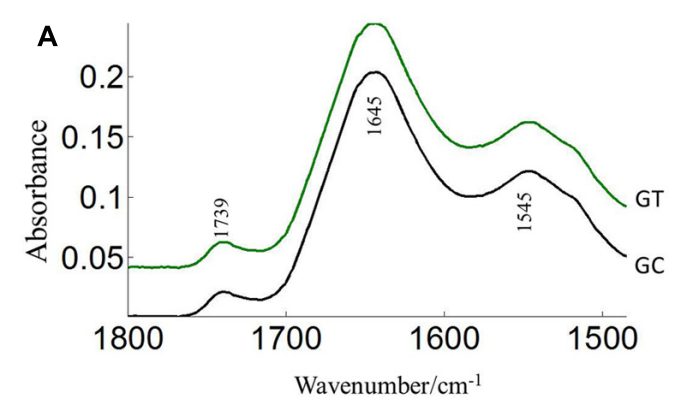

B

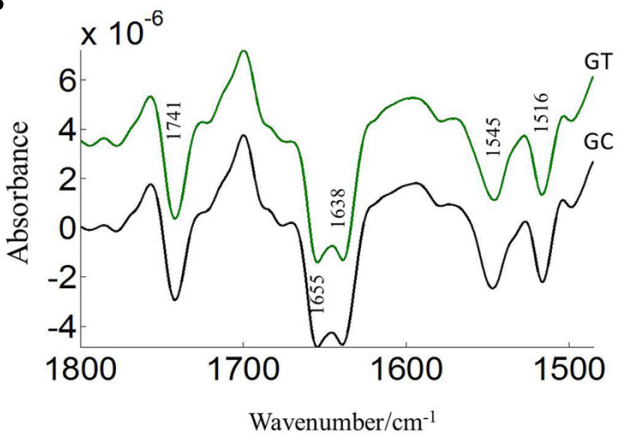

FIGURE 3 | Average protein (1800-1500 $\mathrm{cm}^{-1}$ ) absorbance (A) and second derivative spectra (B) of heat stressed (GT) and control (GC) pollen of CDC Golden. Data are means of 15 individual pollen spectra per treatment combination.

a resolution enhancement technique to separate the overlapping bands. Before running the curve fitting we input the minimum and maximum wavenumber range for each peak based on the second derivative spectrum which is presented in the Table 2 . The area of each peak was initialized manually based on the second derivative and than did the auto run by using the mixture of Lorentzian and Gaussian lineshapes which resulted the multi component peak and combination of this multi peak (blue) well overlapped with the original spectrum (Figures 4 and 5). The cpercent of each protein secondary structures is presented in Table 2.

Bands were assigned to $\beta$-sheets, $\alpha$-helical structure, and random coils or loops as above (Figures 4 and 5). The contributions by various protein secondary structures to the protein-rich matrix of pollen coat were estimated and interesting differences were observed in $\alpha$-helical and $\beta$ structures (Table 3 ). The contribution of $\alpha$-helical structure was greater in CDC Sage than CDC Golden in both conditions (control and heat stressed) which may be one of the key components for sustaining heat tolerance. However, there was an increased reduction of $\alpha$-helices in heat stressed CDC Sage. In contrast, the $\beta$-sheet structure was greater in CDC Golden pollen compared to CDC Sage under both conditions of control and high temperature. These differences were also reflected in the content of $\alpha$ to $\beta$ ratio, which was much lower in CDC Golden compared to CDC Sage. Other secondary structural contributions such as random coils or loops in both cultivars were observed more in heat stressed pollen samples than in the control treatment. Heat treatment appeared to affect other protein secondary structures such as (turns and random coils) with 
Table 1 | Integrated absorption peaks of $\mathrm{O}-\mathrm{H}$ stretching-amide $\mathrm{A}\left(3315 \mathrm{~cm}^{-1}\right)$, oxidative stress $\left(=\mathrm{CH}, 3015 \mathrm{~cm}^{-1}\right)$, lipids $\left(3000-2800 \mathrm{~cm}^{-1}\right)$, amide I $\left(1650 \mathrm{~cm}^{-1}\right)$, phosphate $\left(P=0,1240 \mathrm{~cm}^{-1}\right)$, carbohydrates $\left(1053 \mathrm{~cm}^{-1}\right)$, nucleotides $\left(996 \mathrm{~cm}^{-1}\right)$, and other parameters such as esterification ratio and protein ratio in pollen of CDC Golden and CDC Sage under normal $\left(24 / 18^{\circ} \mathrm{C}\right)$ and heat stress.

\begin{tabular}{|c|c|c|c|c|c|}
\hline \multirow{2}{*}{$\begin{array}{l}\text { Peak position } \\
\left(\mathrm{cm}^{-1}\right)\end{array}$} & \multirow{2}{*}{$\begin{array}{l}\text { Wavenumber } \\
\text { range }\left(\mathrm{cm}^{-1}\right)\end{array}$} & \multicolumn{2}{|c|}{ Controls-pea pollen $\left(24 / 18^{\circ} \mathrm{C}\right)$} & \multicolumn{2}{|c|}{ Heat stressed-pea pollen $\left(36 / 18^{\circ} \mathrm{C}\right)$} \\
\hline & & CDC Sage & CDC Golden & CDC Sage & CDC Golden \\
\hline 3015 & $3030-3000$ & $2.7 \pm 0.1$ & $2.8 \pm 0.1$ & $2.8 \pm 0.1$ & $2.9 \pm 0.1$ \\
\hline $3000-2800$ & $3000-2800$ & $3.0 \pm 0.3$ & $3.1 \pm 0.2$ & $3.1 \pm 0.2$ & $3.0 \pm 0.2$ \\
\hline 1240 & $1261-1200$ & $0.83 \pm 0.05$ & $0.9 \pm 0.1$ & $1.13 \pm 0.07$ & $0.95 \pm 0.06$ \\
\hline 1053 & $1090-1022$ & $7.3 \pm 0.3$ & $7.0 \pm 0.3$ & $7.4 \pm 0.2$ & $7.0 \pm 0.2$ \\
\hline 996 & 1010-960 & $2.6 \pm 0.1$ & $2.7 \pm 0.1$ & $2.5 \pm 0.1$ & $2.7 \pm 0.1$ \\
\hline $1654 / 1638$ & & 1.18 & 0.76 & 0.95 & 0.71 \\
\hline $1740(1760-1720)$ & & 0.13 & 0.36 & 0.19 & 0.38 \\
\hline
\end{tabular}

${ }^{*}$ Esterification ratio $(\%)=1740 /(1740+1650) \times 100 ; *$ Standard errors $(n=15)$.

a prominent increase in CDC Golden pollen (control and heat stressed), while no corresponding change was observed in CDC Sage pollen.

\section{PEA POLLEN LIPIDS}

Three prominent areas in the lipid region were chosen for comparison between the two cultivars: $3050-3000 \mathrm{~cm}^{-1}(=\mathrm{CH})$, 3000-2800 $\mathrm{cm}^{-1}\left(\mathrm{CH}_{2}\right.$ and $\mathrm{CH}_{3}$ stretching vibrations of lipid acyl chain) and $1760-1720 \mathrm{~cm}^{-1}$ (carbonyl ester) to address the importance of lipids in CDC Sage and CDC Golden pollen (Figures 6 and 7) in control and heat stressed conditions. The band observed at $3015 \mathrm{~cm}^{-1}$ is assigned to $=\mathrm{CH}$ vibration. The bands observed at 2970 and $2876 \mathrm{~cm}^{-1}$ correspond to asymmetric and symmetric stretching vibration of $\mathrm{CH}_{3}$. Similarly, asymmetric and symmetric $\mathrm{CH}_{2}$ vibrations were observed at 2922 and $2852 \mathrm{~cm}^{-1}$. Results showed a strong difference in integrated absorbance of lipid regions between both pea cultivars and also due heat stress. The intensity of asymmetric and symmetric $\mathrm{CH}_{2}$ vibration of heat stressed CDC Golden pollen were considerably reduced in comparison to the control treatment (Figure 6). No such changes were observed in CDC Sage. Since the total lipid content of pollen from each pea cultivar was proportional to the IR absorbance (Griffiths, 1978), we compared the absorbance in the lipids region of both cultivars under control and heat stress conditions after normalization using the amide I region. In the control pollen, the lipid content was higher in CDC Golden than CDC Sage, but with heat stress, the lipid content increased by 0.067 [arbitrary units (a.u.)] in CDC Sage pollen and decreased by 0.096 a.u. in CDC Golden pollen. This suggests that lipids were more affected by heat stress in CDC Golden than CDC Sage (Table 1). Further, the band encoding oxidation stress located at $\sim 3015 \mathrm{~cm}^{-1}$, was greater in CDC Golden pollen than in CDC Sage pollen (Figure 6 and Table 1), even the CDC Golden may be more heat resistant via other mechanisms.
The carbonyl vibrations of esters occur at frequencies between 1760 and $1720 \mathrm{~cm}^{-1}$, and usually provide information about the polar interfacial regions of membrane lipids or pectin (Sowa et al., 1991). By inference, the ratio of areas of the bands at $1740 \mathrm{~cm}^{-1}$ over the sum of the areas of the bands at 1740 and $1650 \mathrm{~cm}^{-1}$ should be proportional to the degree of esterification. This method was applied to evaluate the degree of esterification of pectin cell walls from pollen of both pea cultivars CDC Golden and CDC Sage and to study the changes in the degree of esterification during heat stress. The peak of the ester carbonyl with the vibrational frequencies near to $1740 \mathrm{~cm}^{-1}$ of heat stressed pollen showed changes in intensity with heat stress on both pea cultivars (Table 1). This shows that a high degree of esterification in pollens of CDC Sage or CDC Golden under higher temperature stress with a slight difference between the two cultivars (Figure 7). A shift in the absorption bands in the carbonyl ester region was observed between CDC Golden and CDC Sage indicating changes in the lipids or pectin compositions between the two cultivars.

\section{DISCUSSION}

\section{PEA POLLEN GERMINATION}

Favorable pollen viability and seed set under heat stress are important traits for selection in breeding programs, and there is a strong correlation between pollen production and viability, dehiscence, and seed-set (Bita and Gerats, 2013). Temperature is one of the most important environmental stresses that may limit pollen growth and development (Hedhly et al., 2004; Rang et al., 2011). Temperature stress in the period preceding dehiscence results in more severe consequences for pollen viability than after dehiscence (Rang et al., 2011). Furthermore, both cold and heat stress during pollen development can negatively affect pollen viability depending on the species. The results from this study highlighted the impact of high temperature on pollen germination of two pea cultivars CDC Golden and CDC Sage. The germination rate of CDC Golden pollen decreased with increasing temperatures from 


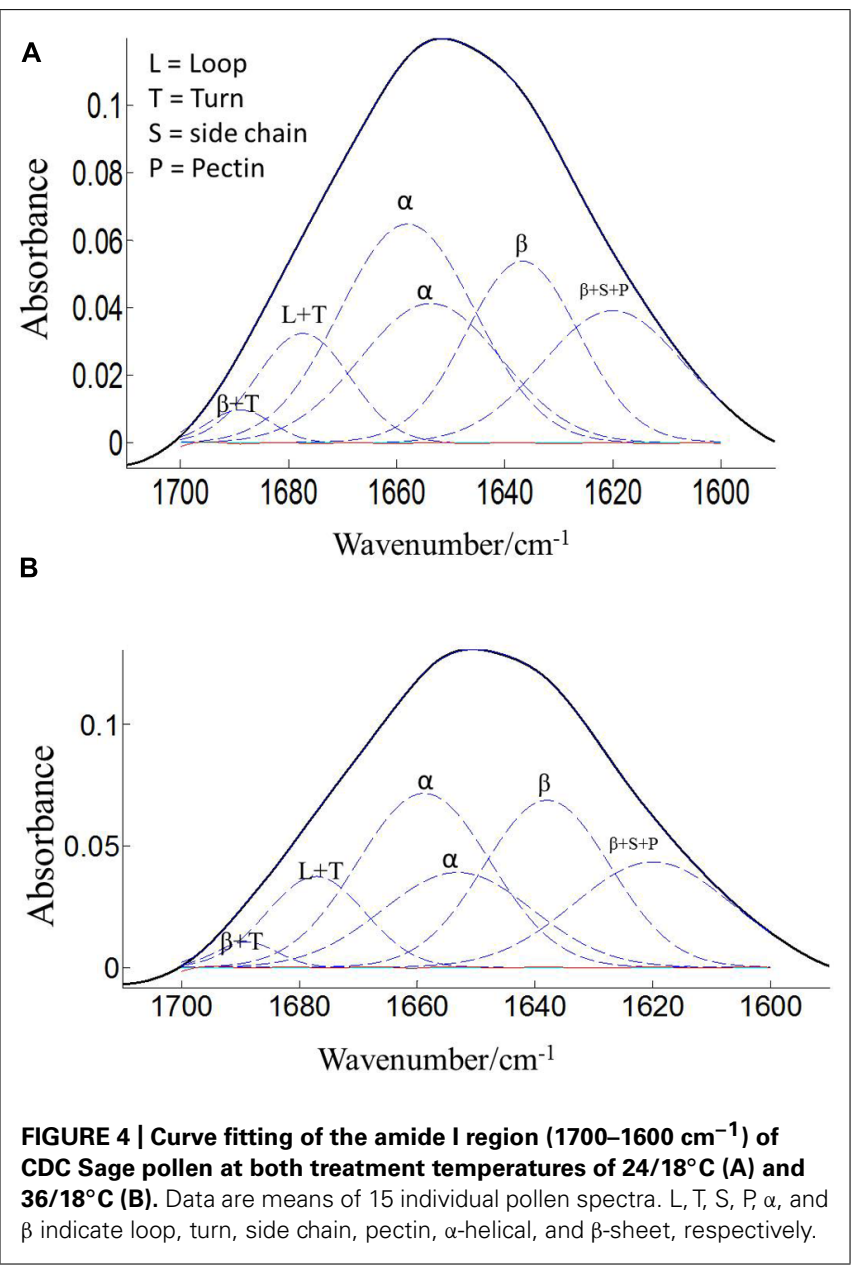

24 to $36^{\circ} \mathrm{C}$. In CDC Sage, the pollen germination percentage was reduced with an increase in temperature from 24 to $36^{\circ} \mathrm{C}$, although the effect was less than that observed in CDC Golden. This result indicated a difference in the response mechanisms of both pea cultivars facing heat stress, which may be related to pollen and pollen wall composition. The effect of heat stress during reproductive development has been thoroughly investigated in different crops. Temperatures between 20 and $25^{\circ} \mathrm{C}$ are reported to be optimal for pollen germination, pollen tube growth, and seed set (Sato et al., 2002; Jagadish et al., 2010; Rang et al., 2011). Surprisingly, raising the temperatures to $29^{\circ} \mathrm{C}$ and above drastically reduced the number of fruits formed and seeds set (Sato et al., 2002). Using male sterile plants, Peet et al. (1998) demonstrated that the effect was largely caused by defects in male reproductive organ development, while female organ development was less affected in tomato plants. In bean, when heat-sensitive and heat-tolerant genotypes were subjected to mild heat stress during development, pollen viability of the heat-sensitive genotype declined from $80 \%$ to below $10 \%$ after 10 days of heat treatment. The heat-tolerant genotype, however, still produced $60 \%$ viable pollen even after 24 days of stress. The effects of heat stress on pollen included alterations in the pollen wall composition and a reduction in the number of pollen grains that adhered to the stigma (Porch and Jahn, 2001).

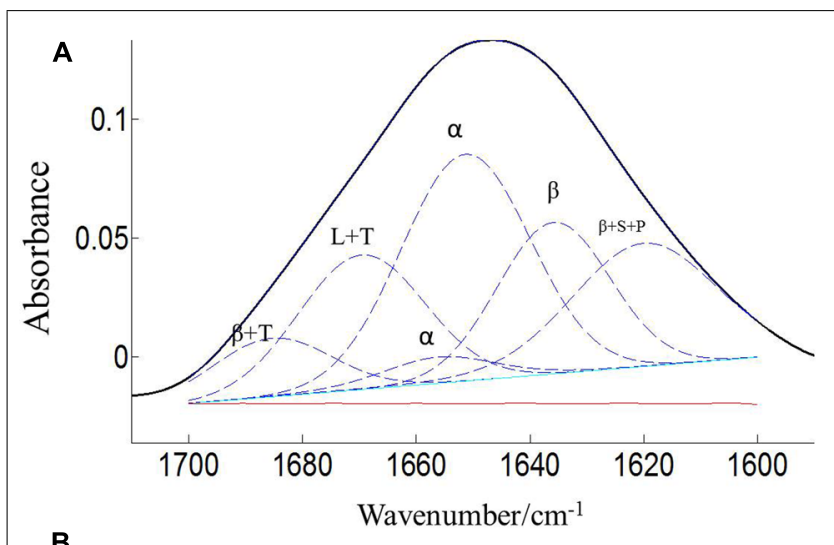

B

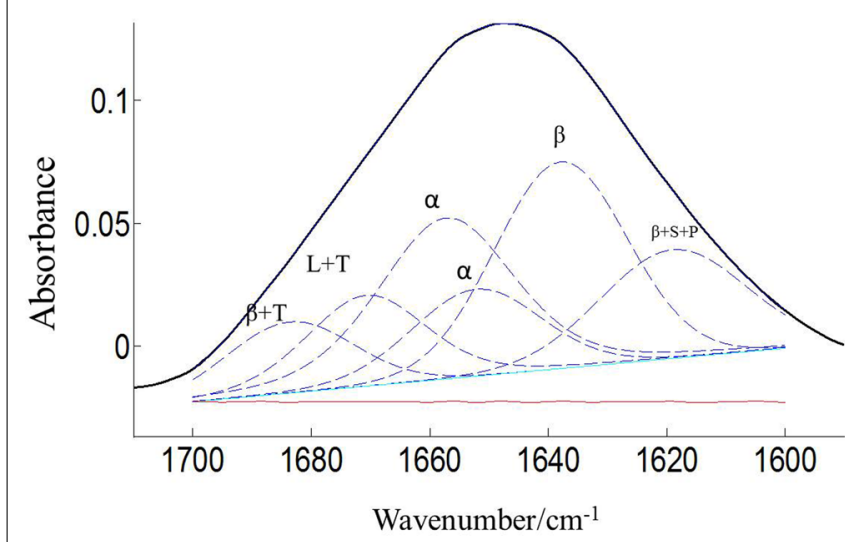

FIGURE 5 | Curve fitting of the amide I region (1700-1600 $\mathrm{cm}^{-1}$ ) of CDC Golden pollen at both treatment temperatures of $24 / 18^{\circ} \mathrm{C}(\mathrm{A})$ and

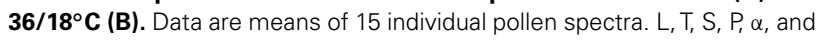
$\beta$ indicate loop, turn, side chain, pectin, $\alpha$-helical, and $\beta$-sheet, respectively.

Table 2 | Selected area are used for curve fitting and protein secondary structure calculation on the basis of second derivative spectrum of pollen pea CDC Golden and CDC Sage.

\begin{tabular}{lll}
\hline Secondary structure content & $\begin{array}{l}\text { Minimum } \\
\text { value }\left(\mathbf{c m}^{-\mathbf{1}}\right)\end{array}$ & $\begin{array}{l}\text { Maximum } \\
\text { value }\left(\mathbf{c m}^{-\mathbf{1}}\right)\end{array}$ \\
\hline$\beta$-sheets + turn & 1682 & 1690 \\
Loop + turn & 1662 & 1678 \\
$\alpha$-helices & 1648 & 1660 \\
$\beta$-sheets & 1630 & 1640 \\
$\beta$-sheets + side chain + pectin & 1610 & 1620 \\
\hline
\end{tabular}

\section{PEA POLLEN PROTEIN}

The pollen coat is a layer of material made up of lipids and proteins which is present on the surface of the pollen wall and it would be sensitive to heat stress (Wolters-Arts et al., 1998). ATRFTIR spectroscopy was used to compare the composition of the pollen coats of two pea cultivars CDC Sage and CDC Golden, and in response to heat stress. The FTIR spectra were used to assess the changes of protein. Comparison of the chemical structure of pollen for both pea cultivars, CDC Sage and CDC Golden 
Table 3 | Secondary protein structure data of pollen of CDC Golden and $\mathrm{CDC}$ Sage at control $\left(24 / 18^{\circ} \mathrm{C}\right)$ and heat stress $\left(36 / 18^{\circ} \mathrm{C}\right)$ conditions.

\begin{tabular}{|c|c|c|c|c|}
\hline \multirow[t]{2}{*}{ Protein structure } & \multicolumn{2}{|c|}{$\begin{array}{l}\text { Control-Pea pollen } \\
\qquad\left(24 / 18^{\circ} \mathrm{C}\right)\end{array}$} & \multicolumn{2}{|c|}{$\begin{array}{l}\text { Heat stressed-pea pollen } \\
\qquad\left(36 / 18^{\circ} \mathrm{C}\right)\end{array}$} \\
\hline & CDC Sage & CDC Golden & CDC Sage & CDC Golden \\
\hline$\beta$-sheet & $41.3^{*}$ & 46.3 & 46.0 & 51.7 \\
\hline$\alpha$-helix & 48.6 & 35.3 & 43.6 & 36.2 \\
\hline others & 10.1 & 18.4 & 10.4 & 12.0 \\
\hline
\end{tabular}

Data were estimated from the average spectra of 15 individual pollen grains per treatment combination.

* Percentage with respect to $100 \%$ of total protein structures; others represent loops, turns, and pectin.

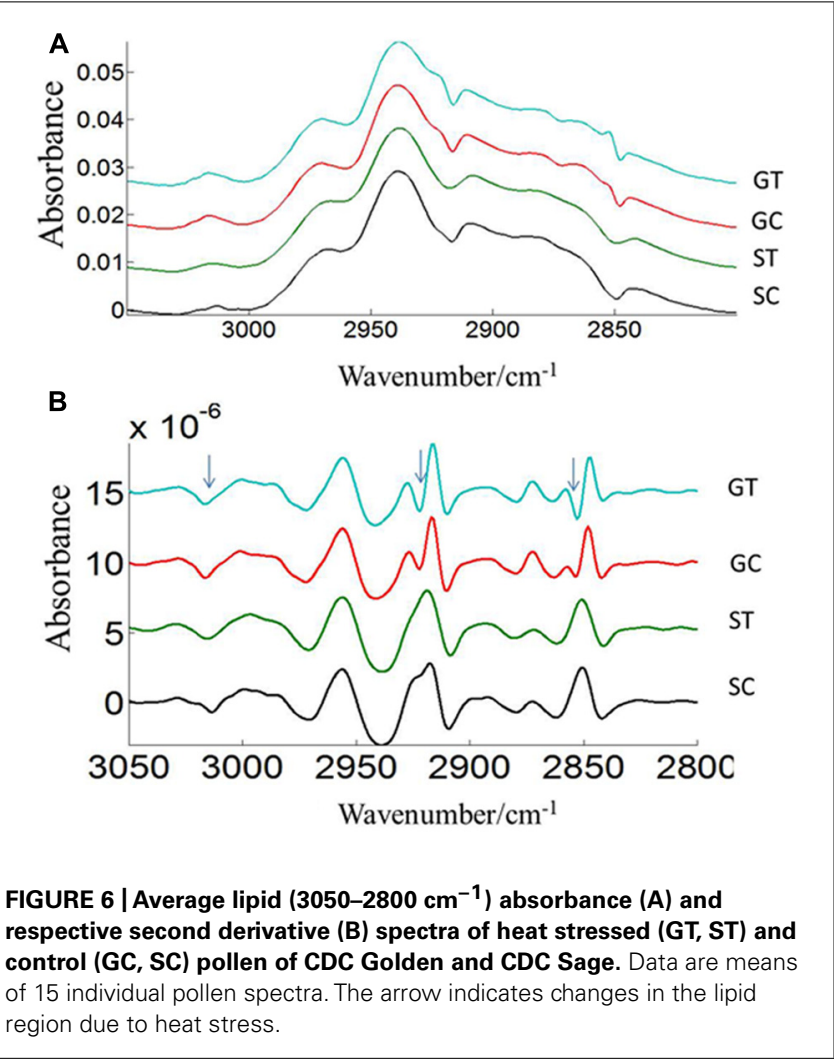

revealed that they exhibit similar responses to heat stress, although the severity of the effect differed between the two pea cultivars. In general, the composition of amide I bands observed in whole pollen of both pea cultivars represented different types of protein secondary structures. The band at $\sim 1654 \mathrm{~cm}^{-1}$ was assigned to $\alpha$-helical structures, because $\alpha$-helical vibrations are usually observed between 1650 and $1658 \mathrm{~cm}^{-1}$ (Haris and Chapman, 1992; Wolkers and Hoekstra, 1995). The curve fitting results of amide I region of pollen underline considerable differences between whole pollen grains of both cultivars in the presence and absence of heat stress. In control grains, the contribution of $\alpha$-helical structures were more important in the whole pollen of CDC Sage (48.6\%) than in CDC Golden (35.3\%). This is

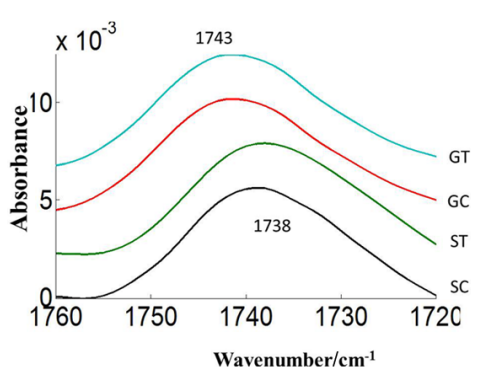

FIGURE 7 | Average carbonyl esters (1760-1720 cm-1) absorbance spectra of heat stressed (ST, GT) and control (SC, GC) pollen of pea cultivar CDC Sage and CDC Golden, respectively. Data are means of 15 individual pollen spectra per treatment combination.

in agreement with the contribution of $\alpha$-helical structures in in vitro cattail pollen as reported previously by Wolkers and Hoekstra (1995). When whole pollen grains were subjected to in vivo heat stress, the contribution of $\alpha$-helical structures was reduced from 48.6 to $43.6 \%$ in CDC Sage pollen but the content was still higher than that observed in CDC Golden. Wolkers and Hoekstra (1995) stated that the presence of $\alpha$-helical domains protected bulk proteins in pollen against destructive effects of dehydration. The decrease of $\alpha$-helical structures in the whole pollen of CDC Sage when subjected to heat stress may compensate for the reduced protein-water hydrogen band which may have explained its higher germination rate $(60 \%)$. Therefore, the presence of low amounts of $\alpha$-helical domains in whole pollen of CDC Golden may explain its sensitivity to heat stress as demonstrated by low pollen germination rate. In addition, the intensity of the oxidation band at $\sim 3015 \mathrm{~cm}^{-1}$ was higher in CDC Golden than CDC Sage and increased with heat stress (Table 1), indicating that CDC Golden may have been affected by heat stress to a larger degree than CDC Sage. However, further analysis of cellular extracts of pollen from both pea cultivars is required and is planned in our future work to differentiate between membrane and cytoplasmic proteins as well as to test more varieties to quantify how changes in chemical molecular composition of pea cultivars pollens are linked to heat stress tolerance.

\section{PEA POLLEN LIPIDS}

Lipids play an important role in pea pollen germination (Dickinson et al., 2000). The pea pollen surface lipid composition detected by ATR spectroscopy was likely from the pollen coat and sporopollenin on the exine layer. The exine lipid may have changed under heat stress in pea (cv. CDC Golden) and may have affected pollination events including pollen contact, adhesion and attachment of pollen to the stigma. Such a lipid change can affect pollen hydration, pollen germination, pollen tube growth through the stigma, style, and ovary, and fertilization of the ovule. This study demonstrated a difference in the lipids region due to heat stress and treated pollen from CDC Golden which was not observed in CDC Sage (Figure 6). This suggests that lipids were more affected by heat stress in CDC Golden than CDC Sage. This was confirmed by the considerable reduction 
of asymmetric and symmetric $\mathrm{CH}_{2}$ peaks in heat stressed samples (Figure 6B). Porch and Jahn (2001) have remarked that high temperatures may result in the structural modification of the exine layer of common bean pollen. The external pollen cell wall, exine, protects the pollen grain from environmental damage and dehydration and also facilitates pollen-stigma interactions, pollen hydration, and release of the pollen tube to effect fertilization (Mach, 2012). The exine is largely formed from acyl lipids and phenylpropanoid precursors. These two main components that are synthesized in the tapetum form the stable biopolymer sporopollenin structure of the exine (Piffanelli et al., 1998). Both the exine coating of the pollen grain and the dry surface of the stigma affect pollen adhesion to the stigma (Herscovitch and Martin, 1989). After pollen adhesion to the stigma and formation of a hydration lens, the outer exine coating flows out and forms a "foot" to establish attachment at the point of pollen-stigma contact (Scott, 1994). Availability of high amounts of lipids are mandatory for pea pollination, including different steps from pollen germination to pollen-attachment and adhesion stigma contact. Consequently, the difference in lipid amounts in whole pollen between the two pea cultivars after heat stress may contribute to a better explanation of pollen germination percentage differences observed in this study. This observation is in agreement with a greater amount of amide I in pollen of CDC Sage compared to CDC Golden that may prevent the loss of hydrogen bonds during heat stress which is highly correlated with the results shown for $\alpha$-helical domain structures. In a recent study, Zimmermann and Kohler (2014) determined that IR spectra showed larger inter-annual variations in pollen composition of pine trees and these variations were predominantly due to differences in lipid content. They determined that pollen lipid patterns had a strong correlation with temperature profiles prior to pollination starting dates. Similarly, Wolters-Arts et al. (1998) reported that lipids are an essential compound needed for pollen tubes to penetrate the stigma, and in the presence of these lipids pollen tubes can even penetrate leaf cuticles. The authors further proposed that lipids direct pollen-tube growth by controlling the flow of water to pollen in species with dry and wet stigma. Accordingly, it would be interesting to further investigate the role of components of the exudate or pollen coat of pea cultivars for pollen tube penetration under heat stress. On the other hand, the spectral absorbance of ester carbonyl regions that are mainly known as pectin contributors were only slightly changed in pollen with increasing temperature in both pea cultivars, suggesting that pectin metabolism did not play a central role in pollen tolerance to heat stress, but its contribution was likely prominent in subsequent pollen tube growth and viability as previously shown by Tian et al. (2006).

\section{CONCLUSION}

Pea has heat resistant mechanisms associated with pollen grains. Genotypes with pollen that has heat resistance have maintained pollen vigor and increased pollen germination, allowing for a greater success in fertilization. Two such mechanisms were evident in the physical structure of pollen, by maintained protein and lipid integrity of the coat. The ATR-FTIR spectroscopy was well adopted as a non-destructive chemical tool for investigating biochemical differences between the pollen grains of two pea cultivars and under environmental stress conditions in vitro like heat stress. Pollen from cultivar CDC Sage had more $\alpha$-helical structures of protein than CDC Golden pollen, which had more $\beta$-sheets. The genotypic differences in pollen between compositions were detected in the lipid regions, and a prominent change was revealed in asymmetric and symmetric $\mathrm{CH}_{2}$ bands in $\mathrm{CDC}$ Golden pollen under heat stress. The bands for lipid, protein, and carbohydrates were different between the two cultivars and varied with heat stress. Additionally, the band corresponding to oxidative stress was much higher in CDC Golden pollen than CDC Sage pollen with heat stress. These findings may explain the difference in pollen germination between both pea cultivars under heat stress. Our results underline changes in the composition of major biomolecules (proteins, lipids, and carbohydrates) of pea pollen grains, which may be indicators of heat stress tolerance, and results may also indicate dual or separate roles of protein and lipids. Therefore, further investigations are planned to confirm the correlation between the in vivo pollen viability and pollen molecular composition by assessing the viability of pollen after in vivo heat stress on more pea varieties.

\section{AUTHOR CONTRIBUTIONS}

Rachid Lahlali, Yunfei Jiang, Chithra Karunakaran, and Rosalind Bueckert conceived this research. Rachid Lahlali, Chithra Karunakaran, Yunfei Jiang, and Saroj Kumar collected and analyzed output data. Xia Liu and Ferenc Borondics helped in FTIR setup and data collection. Emil Hallin and Rosalind Bueckert supervised the work. Rachid Lahlali and Saroj Kumar wrote the manuscript and all authors contributed to the manuscript revision.

\section{ACKNOWLEDGMENTS}

We acknowledge Agricultural Development Fund of Saskatchewan for funding this research program under Grant No. ADF20130054. The authors thank Mr. Royal Hinther of Canadian Light Source who provided expert advice related to plant measurements. The research described in this paper was performed at the Canadian Light Source which is funded by the Canada Foundation for Innovation, the Natural Sciences and Engineering Research Council of Canada, the National Research Council Canada, the Canadian Institutes of Health Research, the Government of Saskatchewan, Western Economic Diversification Canada, and the University of Saskatchewan.

\section{REFERENCES}

Alonso-Simon, A., Encina, A. E., Garcia-Angulo, P., Alvarez, J. M., and Acebes, J. L. (2004). FTIR spectroscopy monitoring of cell wall modifications during the habituation of bean (Phaseolus vulgaris L.) callus cultures to dichlobenil. Plant Sci. 167, 1273-1281. doi: 10.1016/j.plantsci.2004. 06.025

Bernier, M. H., Levy, G. J., Fine, P., and Borisover, M. (2013). Organic matter composition in soils irrigated with treated wastewater: FT-IR spectroscopic analysis of bulk soil samples. Geoderma 209, 233-240. doi: 10.1016/j.geoderma.2013.06.017 Bita, C. E., and Gerats, T. (2013). Plant tolerance to high temperature in a changing environment: scientific fundamentals and production of heat stress-tolerant crops. Front. Plant Sci. 4:273. doi: 10.3389/fpls.2013.00273

Bruckman, V. J., and Wriessnig, K. (2013). Improved soil carbonate determination by FT-IR and X-ray analysis. Environ. Chem. Lett. 11, 65-70. doi: 10.1007/s10311012-0380-4 
Buta, J. G., Qi, L., and Wang, C. Y. (1997). Fourier transform infrared spectra of zucchini squash stored at chilling or non-chilling temperatures. Environ. Exp. Bot. 38, 1-6. doi: 10.1016/S0098-8472(96)01059-3

Chamel, A., and Marechal, Y. (1992). Characterization of isolated plant cuticles using Fourier-Transform Infrared (FTIR) spectroscopy. C. R. Acad. Sci. Paris 315, 347-354.

Cicek, E., and Tilki, F. (2007). Seed germination of three Ulmus species from Turkey as influenced by temperature and light. J. Environ. Biol. 28, 423-425.

Dickinson, H. G., Elleman, C. J., and Doughty, J. (2000). Pollen coatings chimaeric genetics and new functions. Sex. Plant Reprod. 12, 302-309. doi: 10.1007/s004970050199

Fernandes, J. C., Garcia-Angulo, P., Goulao, L. F., Acebes, J. L., and Amancio, S. (2013). Mineral stress affects the cell wall composition of grapevine (Vitis vinifera L.). Plant Sci. 205, 111-120. doi: 10.1016/j.plantsci.2013.01.013

Filip, Z. K., Demnerova, K., and Herrmann, S. (2006). "FT-IR spectroscopical detection of some molecular structures in soil microorganisms," in Proceedings of the Bio Micro and Nanosystems Conference, 2006 (San Francisco, CA: IEEE), 80. doi: 10.1109/BMN.2006.330884

Goormaghtigh, E., Cabiaux, V., and Ruysschaert, J. M. (1990). Secondary structure and dosage of soluble and membrane proteins by attenuated total reflection Fourier-transform infrared spectroscopy on hydrated films. Eur. J. Biochem. 193, 409-420. doi: 10.1111/j.1432-1033.1990. tb19354.x

Goormaghtigh, E., Ruysschaert, J. M., and Raussens, V. (2006). Evaluation of the information content in infrared spectra for protein secondary structure determination. Biophys. J. 90, 2946-2957. doi: 10.1529/biophysj.105. 072017

Griffiths, P. R. (1978). Fourier transform infrared spectroscopy: recent developments. Appl. Opt. 17, 1315-1317. doi: 10.1364/AO.17.001315

Guilioni, L., Wery, J., and Tardieu, F. (1997). Heat stress-induced abortion of buds and flowers in pea: is sensitivity linked to organ age or to relations between reproductive organs? Ann. Bot. 80, 159-168. doi: 10.1006/anbo.1997. 0425

Hall, A. E. (1990). Breeding for heat tolerance - an approach based on whole-plant physiology. HortScience 25, 17-19.

Hall, A. E. (1993). "Physiology and breeding for heat tolerance in cowpea, and comparison with other crops," in Adaptation of Food Crops to Temperature and Water Stress, ed. C. G. Kuo (Shanhua: Asian Vegetable Research and Development Center), 271-284.

Haris, P. I., and Chapman, D. (1992). Does Fourier-transform infrared-spectroscopy provide useful information on protein structures. Trends Biochem. Sci. 17, 328 333. doi: 10.1016/0968-0004(92)90305-S

Hedhly, A., Hormaza, J. I., and Herrera, M. (2004). Effect of temperature on pollen tube kinetics and dynamics in sweet cherry, Prunus avium (Rosaceae). Am. J. Bot. 91, 558-564. doi: 10.3732/ajb.91.4.558

Herscovitch, J. C., and Martin, A. R. H. (1989). Pollen-pistil interactions in Grevillea banksii - the pollen grain, stigma, transmitting tissue and in vitro pollinations. Grana 28, 69-84. doi: 10.1080/00173138909429958

Ivanova, D. G., and Singh, B. R. (2003). Nondestructive FTIR monitoring of leaf senescence and elicitin-induced changes in plant leaves. Biopolymers 72, 79-85. doi: 10.1002/bip.10297

Jagadish, S. V. K., Muthurajan, R., Oane, R., Wheeler, T. R., Heuer, S., Bennett, J., et al. (2010). Physiological and proteomic approaches to address heat tolerance during anthesis in rice (Oryza sativa L.). J. Exp. Bot. 61, 143-156. doi: 10.1093/jxb/ erp289

Kong, J., and Yu, S. (2007). Fourier transform infrared spectroscopic analysis of protein secondary structures. Acta Biochim. Biophys. Sin. (Shanghai) 39, 549-559. doi: $10.1111 / \mathrm{j} .1745-7270.2007 .00320 . \mathrm{x}$

Mach, J. (2012). Open wide! Exine patterning and aperture formation in Arabidopsis pollen. Plant Cell 24, 4311-4311. doi: 10.1105/tpc.112.241110

Nielsen, C. L., and Hall, A. E. (1985). Responses of cowpea (Vigna unguiculata (L) Walp.) in the field to high night air temperature during flowering II. Plant responses. Field Crops Res. 10, 181-196. doi: 10.1016/0378-4290(85) 90025-5

Oberreuter, H., Seiler, H., and Scherer, S. (2002). Identification of coryneform bacteria and related taxa by Fourier-transform infrared (FT-IR) spectroscopy. Int. J. Syst. Evol. Microbiol. 52, 91-100.
Oliveira, H., Barros, A. S., Delgadillo, I., Coimbra, M. A., and Santos, C. (2009). Effects of fungus inoculation and salt stress on physiology and biochemistry of in vitro grapevines: emphasis on sugar composition changes by FT-IR analyses. Environ. Exp. Bot. 65, 1-10. doi: 10.1016/j.envexpbot.2008. 05.003

Peet, M. M., Sato, S., and Gardner, R. G. (1998). Comparing heat stress effects on male-fertile and male-sterile tomatoes. Plant Cell Environ. 21, 225-231. doi: 10.1046/j.1365-3040.1998.00281.x

Piffanelli, P., Ross, J. H. E., and Murphy, D. J. (1998). Biogenesis and function of the lipidic structures of pollen grains. Sex. Plant Reprod. 11, 65-80. doi: 10.1007/s004970050122

Porch, T. G., and Jahn, M. (2001). Effects of high-temperature stress on microsporogenesis in heat-sensitive and heat-tolerant genotypes of Phaseolus vulgaris. Plant Cell Environ. 24, 723-731. doi: 10.1046/j.1365-3040.2001. 00716.x

Rang, Z. W., Jagadish, S. V. K., Zhou, Q. M., Craufurd, P. Q., and Heuer, S. (2011). Effect of high temperature and water stress on pollen germination and spikelet fertility in rice. Environ. Exp. Bot. 70, 58-65. doi: 10.1016/j.envexpbot.2010. 08.009

Rao, G. U., Jain, A., and Shivanna, K. R. (1992). Effects of high-temperature stress on Brassica pollen - viability, germination and ability to set fruits and seeds. Ann. Bot. 69, 193-198.

Salem, M. A., Kakani, V. G., Koti, S., and Reddy, K. R. (2007). Pollen-based screening of soybean genotypes for high temperatures. Crop Sci. 47, 219-231. doi: 10.2135/cropsci2006.07.0443

Sato, S., Peet, M. M., and Thomas, J. F. (2002). Determining critical pre- and post-anthesis periods and physiological processes in Lycopersicon esculentum Mill. exposed to moderately elevated temperatures. J. Exp. Bot. 53, 1187-1195. doi: 10.1093/jexbot/53.371.1187

Scott, R. J. (1994). "Pollen exine - the sporopollenin enigma and the physics of pattern," in Molecular and Cellular Aspects of Plant Reproduction, Society for Experimental Biology Seminar Series, Vol. 55, eds R. J. Scott and A. D. Stead (Cambridge: Cambridge University Press), 49-82. doi: 10.1017/CBO9780511752339.006

Shivanna, K. R., and Rangaswamy, N. S. (1992). Pollen Biology: A Laboratory Manual. Berlin: Springer-Verlag. doi: 10.1007/978-3-64277306-8

Sowa, S., and Connor, K. F. (1995). Biochemical-changes during pollen germination measured in vivo by infrared-spectroscopy. Plant Sci. 105, 23-30. doi: 10.1016/0168-9452(94)04036-G

Sowa, S., Connor, K. F., and Towill, L. E. (1991). Temperature-changes in lipid and protein-structure measured by Fourier-transform infrared spectrophotometry in intact pollen grains. Plant Sci. 78, 1-9. doi: 10.1016/0168-9452(91) 90155-2

Taylor, L. P., and Hepler, P. K. (1997). Pollen germination and tube growth. Annu. Rev. Plant Physiol. Plant Mol. Biol. 48, 461-491. doi: 10.1146/annurev.arplant.48.1.461

Tian, G. W., Chen, M. H., Zaltsman, A., and Citovsky, V. (2006). Pollen-specific pectin methylesterase involved in pollen tube growth. Dev. Biol. 294, 83-91. doi: 10.1016/j.ydbio.2006.02.026

Tilki, F., and Dirik, H. (2007). Seed germination of three provenances of Pinus brutia (Ten.) as influenced by stratification, temperature and water stress. J. Environ. Biol. 28, 133-136.

Wahid, A., Gelani, S., Ashraf, M., and Foolad, M. R. (2007). Heat tolerance in plants: an overview. Environ. Exp. Bot. 61, 199-223. doi: 10.1016/j.envexpbot.2007.05.011

Winder, C. L., and Goodacre, R. (2004). Comparison of diffuse-reflectance absorbance and attenuated total reflectance FT-IR for the discrimination of bacteria. Analyst 129, 1118-1122. doi: 10.1039/b408169b

Wolkers, W. F., and Hoekstra, F. A. (1995). Aging of dry desiccation-tolerant pollen does not affect protein secondary structure. Plant Physiol. 109, 907-915.

Wolkers, W. F., and Hoekstra, F. A. (1997). Heat stability of proteins in desiccation-tolerant cattail (Typha latifolia L) pollen - a Fourier transform infrared spectroscopic study. Comp. Biochem. Physiol. A Physiol. 117, 349-355. doi: 10.1016/S0300-9629(96)00274-5

Wolters-Arts, M., Lush, W. M., and Mariani, C. (1998). Lipids are required for directional pollen-tube growth. Nature 392, 818-821. doi: 10.1038/ 33929 
Zhao, D. L., Reddy, K. R., Kakani, V. G., and Reddy, V. R. (2005). Nitrogen deficiency effects on plant growth, leaf photosynthesis, and hyperspectral reflectance properties of sorghum. Eur. J. Agron. 22, 391-403. doi: 10.1016/j.eja.2004.06.005

Zimmermann, B., and Kohler, A. (2014). Infrared spectroscopy of pollen identifies plant species and genus as well as environmental conditions. PLoS ONE 9:e95417. doi: 10.1371/journal.pone.0095417

Conflict of Interest Statement: The authors declare that the research was conducted in the absence of any commercial or financial relationships that could be construed as a potential conflict of interest.

Received: 22 September 2014; accepted: 07 December 2014; published online: 22 December 2014.
Citation: Lahlali R, Jiang Y, Kumar S, Karunakaran C, Liu X, Borondics F, Hallin E and Bueckert $R$ (2014) ATR-FTIR spectroscopy reveals involvement of lipids and proteins of intact pea pollen grains to heat stress tolerance. Front. Plant Sci. 5:747. doi: 10.3389/fpls.2014.00747

This article was submitted to Plant Biophysics and Modeling, a section of the journal Frontiers in Plant Science.

Copyright (ㅇ 2014 Lahlali, Jiang, Kumar, Karunakaran, Liu, Borondics, Hallin and Bueckert. This is an open-access article distributed under the terms of the Creative Commons Attribution License (CC BY). The use, distribution or reproduction in other forums is permitted, provided the original author(s) or licensor are credited and that the original publication in this journal is cited, in accordance with accepted academic practice. No use, distribution or reproduction is permitted which does not comply with these terms. 